\title{
Correction to: Measurement uncertainty: requirements set in the accreditation standards
}

\author{
Kyriacos C. Tsimillis ${ }^{1}$ (D)
}

Published online: 30 May 2018

(C) Springer-Verlag GmbH Germany, part of Springer Nature 2018

\section{Correction to: Accreditation and Quality Assurance (2018) 23:109-114 https://doi.org/10.1007/ s00769-018-1310-3}

Unfortunately, the references 12 and 13 were incorrectly published in the original publication. The correct references are:

12. ISO/IEC 17011 (2017) Conformity assessmentrequirements for accreditation bodies accrediting conformity assessment bodies. International Organization for Standardization/International Electrotechnical Committee, Geneva

13. ISO/IEC 17011 (2004) Conformity assessmentgeneral requirements for accreditation bodies accrediting conformity assessment bodies. International Organization for Standardization/International Electrotechnical Committee, Geneva. Superseded by ISO/IEC 17011 (2017)

The original article can be found online at https:// doi.org/10.1007/s00769-018-1310-3.

Kyriacos C. Tsimillis

ktsimillis@cytanet.com.cy

1 Division of Quality Assurance, Pancyprian Union of

Chemists, 10, E.Pallikaridis Str, 1071 Nicosia, Cyprus 